IJIET, e-ISSN 2548-8430, p-ISSN 2548-8422, Vol. 2, No. 2, July 2018

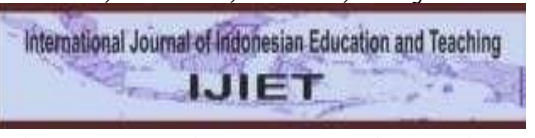

International Journal of Indonesian Education and Teaching http://e-journal.usd.ac.id/index.php/IJIET

Sanata Dharma University, Yogyakarta, Indonesia

\title{
CONNECTING ENGLISH LANGUAGE TEACHING WITH 12 BRAIN/MIND LEARNING PRINCIPLES
}

\author{
Jorge Correa Rodriguez \\ Central China Normal University \\ jorgecorrear@yahoo.com \\ https://doi.org/10.24071/ijiet.v2i2.1260 \\ received 2 May 2018; revised 26 June 2018; accepted 3 July 2018
}

\begin{abstract}
On a daily basis, teachers all over the world modify their students' brain when they teach the contents that the students need to learn; this biological, cognitive and behavioral process is called learning. From a biological, cognitive and educational point of view, those modifications are totally necessary for the development of the learners. One of those so called brain-modification experiences occur when they learn English. Then, how could these modifications (learning) be enhanced? To answer this question, this paper suggests a connection between $12 \mathrm{brain} / \mathrm{mind}$ learning principles and English teaching aiming to make it more effective. The reason is that if teachers become aware of the way the brain learns, their practices may be enhanced leading to more effective teaching and learning. Thus, in order to state this connection, every principle is presented, described and followed by some general practical suggestions related to English teaching. It is necessary to mention that all the included suggestions are examples; it would be the task of the reader and of the teacher to ignite her creativity by applying the principles in her particular context to enhance her teaching practices and promote English learning among students.
\end{abstract}

Keywords: brain principles, English teaching, language learning, teaching

\section{Introduction}

Teachers, all over the world, employ a variety of methods and strategies every day. Some of them may rely on academically-grounded and mainly conventional ones, while others may use a mixture of the latter plus empirical ones based on their own and successful experiences. In any case, both will aim to promote effective teaching therefore effective learning. Effective language teaching, specifically English, has a strong background of fundamental methods and principles to guide its instruction (Brown, 2000; Celce-Murcia, 2001; Krashen, 1982; Richards \& Renandya, 2002). All these theories and methods have proven to be effective in most contexts because they state general language learning principles. Most of those principles and theories are rooted on human psychological and cognitive skills needed to learn, in this very case, languages.

As mentioned earlier, teachers modify their students' brain every time they teach them something. As Tokuhama-Espinosa (2014) reflected “...by simply 
sitting in a classroom...a student is bound to learn" (p. xxxii). She reached this conclusion when analyzing the effects of several teaching methodologies encased in the theory of visible learning (Hattie \& Yates, 2014). In that way, all teaching

may produce some kind of modification in the students' brain if we consider learning as a biological and cognitive change in our body. As Zull (2002) suggested, "learning is change. It is change in ourselves, because it is change in the brain. Thus, the art of teaching must be the art of changing the brain." (p. xiv). The idea of teachers as experts in the biology of teaching, therefore specialists in the way the brain learns has been supported by several experts in the area (Blakemore \& Frith, 2005; Erlauer, 2003; Geake, 2009; Howard-Jones, 2014a; Jensen, 2008; Hattie \& Yates, 2014; Rodriguez \& Fitzpatrick, 2014; TokuhamaEspinosa, 2014; Tokuhama-Espinosa, 2011; Willis, 2008; Zull, 2002; Zull, 2011).

In that way, it would be possible to think that the inclusion of updated general brain-based learning principles to support the existing foundations for teaching a language may lead to enhancements in any teaching situation. Thus, 12 brain/mind learning principles will be presented as an option to enhance English language teaching due to their connection with brain research.

\section{Theory}

The main theory underlying this study was derived from the $12 \mathrm{brain} / \mathrm{mind}$ learning principles proposed by researchers that believed that an understanding of the workings of the human brain may lead to effective teaching and learning (Caine, Caine, Klimek, \& McClintic, 2009). They developed a list of 12 learning principles supported by brain research aiming to improve the way teaching is

performed. Their efforts have been validated by studies related to cognitive neuroscience, specifically research conducted on one of its branches related to educational matters called; educational neuroscience or mind, brain and education.

All the studies performed in this area seek to support the science of learning and its applications in education (Blakemore \& Frith, 2005; Erlauer, 2003; Geake, 2009; Howard-Jones, 2014a; Howard-Jones, 2014b; Immordino-Yang \& Damasio, 2007; Jensen, 2008; Medina, 2008; Rodriguez \& Fitzpatrick, 2014;

Tokuhama-Espinosa, 2014; Tokuhama-Espinosa, 2011; Willis, 2008; Zull, 2002; Zull, 2011). It is necessary to mention that despite the efforts, contributions and findings that the experts in this area are making, they have also received criticism leading to interesting discussions on the effective connection between education and brain-science (Bruer, 1997; Bruer, 2016).

\section{The 12 Brain/Mind Learning Principles}

The foundation of the following analysis was mainly supported by the 12 learning principles, which as described by their authors are universal for all human beings (Caine, Caine, Klimek, \& McClintic, 2009). Each principle aims to promote the inclusion of specific aspects critiical to learning. All those aspects arebased on the workings of the brain when it undergoes any learning experience.

Moreover, apart from presenting the 12 principles, their authors arranged them within three distinct elements; relaxed alertness, immersion in complexexperience and active processing. In this way, each principle fits one of the three elements which at the same time provide support for their effectiveness. These 
three elements can be consider as fundamentals aspects of any teaching and learning process. At the same time, they mirror the general aspects found in the theories of how language teaching is supposed to be taught as well as how it hasto be learned (Brown, 2000; Harmer, 2007a; Harmer, 2007b). The three elements and their corresponding 12 principles are presented in table 1 . The order of the principles, within each element, is the same one their authors suggested.

Table 1. The 12 Brain/mind principles within each element

\section{Relaxed Alertness}

Active Processing Experience

(11) Complex learning is enhanced by challenge and inhibited by threat

(2) The brain/mind is social

(3) The search for meaning is innate

(5) Emotions are critical for patterning
(6) The brain/mind processes parts and wholes simultaneously

\section{(1) All learning is} physiological

(4) The searching for meaning occurs through patterning (10) Learning is developmental
(9) There are at least two approaches to memory: archiving isolated facts and skills or making sense of experience

(7) Learning involves both focused attention and peripheral perception

(8) Learning always involves conscious and unconscious processes

(12) Each brain is uniquely organized

Note. The 12 brain/mind learning principles are presented following the same order their authors proposed (Caine, Caine, Klimek, \& McClintic, 2009).

The previous table described the principles based on the three elements, therefore the original order of the principles is presented in table 2 as follows.

Table 2. The 12 brain/mind learning principles.

\begin{tabular}{|c|c|}
\hline Principle 1 & All learning is physiological \\
\hline Principle 2 & The brain/mind is social \\
\hline Principle 3 & The searching for meaning is innate \\
\hline Principle 4 & The searching for meaning occurs through patterning \\
\hline Principle 5 & Emotions are critical for patterning \\
\hline Principle 6 & The brain/mind processes parts and wholes simultaneously \\
\hline Principle 7 & Learning involves both focused attention and peripheral perception \\
\hline Principle 8 & Learning always involves conscious and unconscious processes \\
\hline Principle 9 & $\begin{array}{l}\text { There are at least two approaches to memory: archiving isolated facts and skills } \\
\text { or making sense of experience }\end{array}$ \\
\hline Principle 10 & Learning is developmental \\
\hline Principle 11 & $\begin{array}{l}\text { Complex learning is enhanced by challenge and inhibited by threat associated } \\
\text { with helplesness }\end{array}$ \\
\hline Principle 12 & Each brain is uniquely organized \\
\hline
\end{tabular}

Note. The 12 brain/mind learning principles are presented following the same order their authors proposed (Caine, Caine, Klimek, \& McClintic, 2009). 


\section{Theory Application}

In order to connect English language teaching with the 12 principles, the following arrangement will be followed; the analysis will be presented firstly by stating a connection with each element followed by the reflections of their corresponding principles.

\section{The First Element: Relaxed Alertness}

Language teaching has been recognized by promoting the inclusion of strategies that pay attention to affective factors (Krashen, 1982). They play fundamental roles when learning. In that way, the principles under this element are definitely related to English language learning.

Principle 11. Complex learning is enhanced by challenge and inhibited bythreat

Suggestions: Plan activities in which students use the language in a progressive and challenging manner. It means that they should feel that they improve in the process of learning. For example, when they finally acquire new vocabulary and they are able to use it, they will feel that they beat the content and they will want to know and learn what is next. The (i+1) hypothesis supports this idea (Krashen, 1982). This positive challenge experience will lead them to a feeling of achievement, which consequently may lower their affective filters in a language learning situation. Also, include activities in which the learners feel relaxed, calm, engaged and interested. For instance, include topics they really like, allow them to choose materials and let them be creative. Let them create their owndialogues, writings or choose their readings from a set of sources. All these ideas will allow them to enjoy the learning process by making them feel considered in the decisions of the class. All of them aim to keep their emotional states calmed and threat free.

\section{Principle 2. The brain/mind is social}

Suggestions: There is no doubt that human beings value socialization and rely on it to accomplish goals. If the aim of learning a language is to communicate then we need others to accomplish it. Plan activities in which learners are allowed to work in pairs and in groups. However, even though this practice is generally observed in language learning contexts, its inclusion is sometimes focused on some specific moments of the class. The suggestion then is to overuse socially- based learning activities. Instead of having a moment for socialization and interactive activities, it would be more beneficial to plan a whole session in which learners have the chance to interact while using the language. Similarly to the previous principle, let students use, play and discover features of the language with their peers. In the end, is it not the ultimate goal of language to share ideas with others?

\section{Principle (3). The search for meaning is innate}

Suggestions: Human beings are curious by nature. The need to understand and relate to what is happening around us is definitely a fundamental aspect of ourlives. However, sometimes the learners may feel that what or how they learn is not useful. It is then the aim of the teacher to provide the reasons for learning, to let them know how certain activity or task will allow them to increase their knowledge and improve their skills. They need to be active actors in their own 
learning process. They need to feel and also be aware of the benefits that a certain activity will provide them. Plan activities in which students need to discover, assess, think critically, feel engaged and reach a solution to a given problem. In doing so, it will be their curious nature that facilitates the memory formation leading to learning of the language.

\section{Principle (5). Emotions are critical for patterning}

Suggestions: This principle could explain itself without a reflection. It should be added that emotions are critical to all kind of learning, not only for patterning. Even though people can learn, by mainly memorizing something they do not like, this experience can become a long and strenuous process. The key element to learning comes from within the learners, it does not matter what the teacher does if the learner is not emotionally engaged, and therefore learning without an emotional connection may be impeded. It is then the job of the teacher to ignite those emotions inside the students. How? The previous principles already stated some ways to reach these emotional connections. All activities that will make the student feel interested, included, relaxed and curious will lower the affective filters of the brain. If you are teaching a class where students chose to be there, then you are one step ahead and it may be easier to manage this principle. However, in classes where language is mandatory for all, despite your interests, your aim is to find the ways to put all the benefits of the principles to promote, firstly, the interest of the learners, if you succeed at getting it, then you and your students are ready to go.

\section{The Second Element: Immersion in Complex Experience}

The emotionally and cognitively immersion in learning experiences facilitates the way learning is processed in the brain. Learners need to be active participants in the classroom, especially in language learning situations. In consequence, teachers need to pay attention to those activities that allow learners to be actively involved.

\section{Principle (6). The brain/mind processes parts and wholes simultaneously}

Suggestions: The nature of the workings of the brain and mind are inherently related. The way they both allow us to understand the world is critical. In that sense, the way they operate together and/or individually can be considered as fundamental parts of the way we perceive and experence reality. When we learn, we observe, assess and internalize the parts and the whole of the experiences we encounter. In the language classroom, teachers need to make sure that all learners understand the whole idea supporting the content they are learning as well as how its constituents parts interact to produce meaning. To be more specific, in english language learning, and from a gramatically point of view, the tenses have auxiliaries that allow words in sentences to obtain meaning related to time. Thus, students need to know how this parts will promote their accurate production of language in the correct tense to transmit the appropiate meaning in that specific timed-bound context.

\section{Principle (6) All learning is physiological}

Suggestions: When people learn, their whole body is receiving stimuli from the outside world. At the same time, their inner bodies are also experiencing several changes. It would be then possible to think that any effective learning 
experience must guarantee the inclusion of the whole physiology. Plan activities that require learners to engage all their senses, be able to perform physical activities or games related to the contents. These ideas may lead to active learning experiences that will facilitate the body to receive several ways to identify, code and retain the stimulus being presented. The multiple asssociations that the senses and the physical experiences will permit to integrate the content from different perspectives. Use role-playing, acting and games that require movements to involve the whole body of the student in the learning process.

\section{Principle (4). The searching for meaning occurs through patterning}

Suggestions: In simple words, neurons in the brain work by creating connections called synapses. Most of the information we receive will be linked and storaged in that way, through connections. Plan lessons that allow students to connect what they know with the contents they will have to learn. Let and guide them to find patterns, similarities and differences in the topic they are learning as well as relate them with what they have already learned. Most teachers know the impact that previous knowledge in any learning experience has. Instead of presenting a new topic in isolation, you should relate it to the things they have already studied. Set this as the base for the new knowldege. The findings of patterns and relationships within the contents will enhance the way new memories are created because neurons that wire together fire together (Hebb, 1949). It means that patterning create connections that once reactivated will produce faster recalling of the iformation. The more connections created for one content may lead to better memorization and recalling.

\section{Principle (10). Learning is developmental}

Suggestions: Language teachers know that the language level of the students will direct and guide the planning of the lessons. The level and complexity of the contents must be related to the cognitive development of the learners which is strictly related to the level of english they have. If possible, group learners based on their performance, set standards of achievement for the class and include any type of differentiate instuction. This action, rather than aiming to create differences will aim to promote improvements in the class. Students will get promoted to the next stage once they reach the appropiate and required level. Takediagnostic tests to observe and make decisions according to the students level. Similarly, design different activities for each level within your own class.

\section{The third Element 3: Active Processing}

If students are in the classroom doing their assignments does not mean they are learning. There is a need for active processing of the information in order to reach effective learning. The process must be guided and provided by the teacher. This active processing is strictly related to memory formation, attention and metacognitive aspects of learning.

Principle (9). There are at least two approaches to memory: archiving isolated facts and skills or making sense of experience

Suggestion: This principle deals with the way in which memories are formed in the brain/mind. As mentioned earlier the brain works through connections. In that way, include in your teaching activities that allow learners to go beyond the simple rote memorization of vocabulary and grammatical into the inclusion of 
different events to enhance remembering and memorization. The idea is to try mix the way the brain stores the information. Teachers should make the process of memorization fluid, comprehensive and dynamic aiming to provide students with opportunities to make sense of experience. The inclusion of experiencial learning in the way of using language in concrete and real world. Plan acitivities that bring the outside world to the classroom, go beyond the simple memorization of facts and allow students to use language as they would use it in daily conversations.

Principle (7). Learning involves both focused attention and peripheralperception

Suggestion: Attention is critical for learning, without it we cannot learn or at least the process will be more complicated. This principle is guided, by four main factors; interest, novelty, emotion and meaning (Caine, Caine, Klimek, \& McClintic, 2009). Plan lessons that include them all. As mentioned earlier, learners' emotions and interest are fundamental. Moreover, take advantage of novelty. Start the lesson in a different way, do something unexpected, use your voice as an attention caller, gestures, music, feel free to be creative. If you gain their attention they will be ready to learn. In the language classroom, you can create situations in which students learn from the content and the context. There is a hidden attention system that also helps us to learn. We also learn without knowing. We assimilate information from the context eventhough we decide notto pay attention to an specific part of it.

\section{Principle (8). Learning always involves conscious and unconscious processes}

Suggestion: The keyword here is reflection. Most of the time we learn things conciously, some of them are taught while others are somehow absorbed by oursleves. Students' decisions to learn are bound to some of the things prevously described such as attention, affective factors and various mental processes that occur without being noticed. To some extent, the unconcious part of learning occurs when the learner is allowed to reflect and undergo metacognitive processes. This processes allow learners to internalize the contents. Provide students with some thinking time, allow them to reflect on what they have learned. Encourage them to think in the target language, to explain a partner the topics of the class. This may allow the memorization and the internalization of thecontents. Moreover, it will also provide time for social learning. The 1-minute teacher is an easy to apply way to promote and use those self-reflections students did. The 1-minute teachers have the mission to tell a partner, in their own words, what they learned in the class and viceversa.

\section{Principle (12). Each brain is uniquely organized}

Suggestion: Every brain is individually shaped through experience. In that way, all learners may have unique and specialized preferences for learning. Weare not refering to learning styles or multiple intelligences which have beenconsidered as a neuromtyths due to the lack of scientific evidence to support them (Howard-Jones, 2014b). Take advantage of students' preferences by supporting their preferences, however with the same energy guide them to explore those waysof learning they believe are weak at. As mentioned earlier, challenge brings rewards, therefore if we can guide them to improve their weaknesses using their strong ways of learning they will feel satisfied. The concept of differentiated 
instruction comes to play in this principle. Every learner is unique, in terms of level of language, previous experiences, skills and disposition to learn all this is influenced by affective factors. In that way, it would be advisable to include in your language classes alternative assessment to reach and respect all the differences among your students. Include choices, let students decide how they would like to be taught and assessed. If they feel important and included, their disposition to learn may be increased.

\section{Conclusion}

The three elements and their 12 brain/mind learning principles are observed in this analysis aim to promote general and equal ways of learning for all learners. It was then the first intention to propose a connection between them and English language teaching. The aim was to provide educators with 12 fundamentals aspects of how people learn. Secondly it aimed to show a way to how to add these ideas into English teaching. All the suggestions were mainly included as a way to add further explanation to each principle rather than presenting them as the only way to use the principles. As with any theory, method and strategy, it is the educator's mission to contextualize and add her own creativity to them. In education nothing is fixed, nothing is the perfect and ultimate solution to most educational problems. However, we also proposed, through the work supporting this analysis under the 12 principles (Caine, Caine, Klimek, \& McClintic, 2009) that a higher understanding of the human brain may lead to higher opportunities for learning to occur, not only in the English language classes but in all of them.

\section{References}

Blakemore, S.-J., \& Frith, U. (2005). The learning brain: Lessons for education. Oxford: Blackwell.

Brown, H. D. (2000). Principles of language learning and teaching (4th ed.). New York: Pearson Education.

Bruer, J. T. (1997). Education and the brain: A bridge too far. Educational Researcher, 26(8), 4-16.

Bruer, J. T. (2016). Where is educational neuroscience? Educational Neuroscience, $1,1-12$.

Caine, R. N., Caine, G., Klimek, K. J., \& McClintic, C. (2009). 12 Brain/Mind Learning Principles in Action: Developing executive functions of the human brain. California: Corwin Pres.

Celce-Murcia, M. (Ed.). (2001). Teaching English as a second or foreign language (3rd ed.). Boston: Heinle \& Heinle Publishers.

Erlauer, L. (2003). The brain-compatible classroom: Using what we know about learning to improve teaching. Alexandria: Association for Supervision and Curriculum Development

Geake, G. J. (2009). The brain at school. New York: McGraw-Hill Companies.

Harmer, J. (2007b). How to teach English: An introduction to the practice of English language teaching (2nd ed.). Essex: Pearson Education Limited.

Harmer, J. (2007b). The practice of English language teaching (4th ed.). Essex: Pearson Education Limited. 
Hattie, J., \& Yates, G. (2014). Visible learning and the science of how we learn. New York: Routledge.

Hebb, D. O. (1949). The organization of behavior. New York: Wiley.

Howard-Jones, P. A. (2014a). Neuroscience and education: A review of educational interventions and approaches informed by neuroscience. Bristol: Education Endowment Foundation.

Howard-Jones, P. A. (2014b). Neuroscience and education: myths and messages. Nature Neuroscience, 15(12), 817-824.

Immordino-Yang, M. H., \& Damasio, A. (2007). We feel, therefore we learn: The relevance of effective and social neuroscience to education. Mind, brain, and education, 1(1), 3-10.

Jensen, E. (2008). Brain-based learning. Thousand Oaks: Corwin Press.

Krashen, S. D. (1982). Principles and practice in second language acquisition. Oxford: Pergamon Press.

Medina, J. (2008). Brain rules: 12 principles for surviving and thriving at work, home, and school. Seattle: Pear Press.

Richards, J. C., \& Renandya, W. A. (Edits.). (2002). Methodology in language teaching: An anthology of current practice. New York: Cambridge University Press.

Rodriguez, V., \& Fitzpatrick, M. (2014). The teaching brain: An evolutionary trait at the heart of education. New York: The New Press.

Tokuhama-Espinosa, T. (2011). Mind, brain and education science. New York: W.W. Norton \& Company, Inc.

Tokuhama-Espinosa, T. (2014). Making classrooms better: 50 practical applications of mind, brain and education science. New York: Norton.

Willis, J. (2008). How your child learns best. Naperville: Sourcebooks Inc.

Zull, J. E. (2002). The art of changing the brain: Enriching the practice ofteaching by exploring the biology of learning. Virginia: Stylus Publishing, LLC.

Zull, J. E. (2011). From brain to mind using neuroscience to guide change in education. Sterling: Stylus Publishing. 